\title{
Research Paper: Evaluating the Disaster Triage Knowledge of Nurses Personnel in Public Hospitals of Ilam
}

\author{
Heshmatollah Asgari ${ }^{1^{*}}$ (D), Mohammad Reza Omidi² (D, Nabi Omidi³ ${ }^{3}$
}

1. Department of Economy, Faculty of Literature and Human Sciences, Ilam University, Ilam, Iran.

2. Department of Industrial Engineering, Payame Noor University, Tehran, Iran.

3. Department of Management, Payame Noor University, Tehran, Iran.

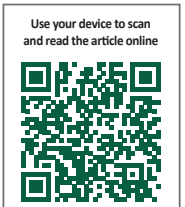

Crtation: Asgari H, Omidi MR, Omidi N. Evaluating the Disaster Triage Knowledge of Nurses Personnel in Public Hospitals of Ilam. Health in Emergencies and Disasters Quarterly. 2018; 4(1):37-42. http://dx.doi.org/10.32598/hdq.4.1.37

http://dx.doi.org/10.32598/hdq.4.1.37

\section{(c) (i) (5)}

Funding: See Page 41

Article info:

Received: 10 Mar 2018

Accepted: 10 Aug 2018

Available Online: 01 Oct 2018

Keywords:

Nurses, Disasters, Triage

\section{A B STRACT}

Background: Educational planning and managing critical situations of accidents and disasters are among the most important issues. Triage, which means the classification of patients and injuries based on specific situations and needs, is one of the important tasks of hospitals at times of disasters. In this study, triage knowledge and practice of nurses working in hospitals affiliated to Ilam University of Medical Sciences are evaluated.

Materials and Methods: This is a cross-sectional and analytic study conducted in 2017 The statistical population comprised all nurses working in Ilam Medical Sciences hospitals. Using Cochran's formula, 174 people were sampled and 160 of them completed the study questionnaires and returned them. The main tool of collecting data was a researcher-made questionnaire based on Canadian triage scale. Validity of the questionnaire was assessed by 10 members of the Ilam University of Medical Sciences. The reliability of the questionnaire was between 0.83 and 0.89 using Cronbach $\alpha$ coefficient. The obtained data were analyzed using descriptive and inferential statistics in SPSS.

Results: The Mean \pm SD duration of nurses' working in the emergency department was $5.2 \pm 3.4$ years, of which $46.2 \%$ had an experience of using triage. The Mean \pm SD score of nurses' knowledge and practice of triage were respectively $10.44 \pm 2.11$ and $9.22 \pm 2.14$ out of 15 . There was no significant relationship between work experience, gender and age with knowledge and practice of triage, but there was a significant relationship between knowledge and practice of nurses about triage with nursing educational degree.

Conclusion: The level of nurses' knowledge and practice of triage in hospitals of Ilam University of Medical Sciences is moderate.

\footnotetext{
* Corresponding Author: 


\section{Introduction}

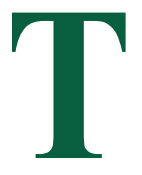

riage is sorting of patients by priority groups for receiving essential aids [1], based on the severity of their conditions. It is done to perform the best practice of the treatment which is one of the most important goals of an emergency department [2]. The goal of triage in disasters with limited medical resources is to provide maximum emergency services to the majority of injured people in the shortest possible time. Appropriate triage in the scene of accident has a direct impact on other practical aspects [3]. The prompt identification of patients with severe illnesses, and rapid implementation of vital measures are possible with triage and prioritization of patients [4]. Although the history of establishing a triage unit in hospitals of Iran dates back to a few years ago, most of the emergency departments in the country have recently started to use this system, which in generally done by nurses [5].

Triage is performed in pre-hospital and in-hospital phases and in normal and critical situations. In normal situations, due to the limited space of hospital, low number of staff and equipment, or in critical situations with increasing number of patients, the ability to treat all patients reduces and patients have to wait longer to receive proper treatments [6]. The pre-hospital triage itself is divided into triage in normal and critical situations. Under normal situations, this kind of triage is based on the answers to three questions: 1 . Is there a need to transfer the patient to the treatment center?; 2. Based on the distance and type, which hospital is more suitable for the patient?; and 3. Which devices and equipment is more suitable for the patient transfer?

The goal of triage is to identify high-risk patients in the accident scene and take immediate actions. In critical situations, the task of triage team is also to evaluate patients quickly, and to take certain health measures and prioritize them for transfer to health centers. In this type of triage, sometimes after initial evaluation and identification of injuries requiring surgery, patients are hospitalized in a place near the operating room and then prioritized by the surgeon to determine the urgency of the surgery. Since the triage is carried out at the scene of an accident, a safe place near the scene are provided and the different areas are distinguished using different colors. Finally, after classification, patients are placed in their own area to receive treatments [7].

In-hospital triage is also divided into triage in normal and critical situations. Triage in normal conditions is generally performed in emergency departments of hospitals with at least 30000 admissions per year [4]. This type of triage is carried out in the shortest possible time based on factors such as patient's vital signs, physical examination, consciousness level, traumatic mechanism, and individual factors such as age and underlying diseases. In critical situations, in-hospital triage is performed at the hospital entrance; i.e. before entering the wards, clinics or emergency room. The triage is performed on the patients outside of the hospital, and each patient is placed in a predetermined area to avoid congestion [2].

Triage in disasters (critical situations) has different goals and processes than triage in normal conditions [7]. In times of disaster, due to the large number of injured people and the limited facilities and services, there is a need for accurate categorization and allocation of services [8].

Iran is a disaster-prone country [9]. Previous crises in Iran have often challenged Iran's disaster management system in coping with disasters and their complications [10]. When an incident occurs, the greatest demand for healthcare services is within the first 24 hours after occurrence, and $85 \%$ to $95 \%$ of the survivors are found in the first 24 hours after disasters [11]. Therefore, during disasters, Iranian hospitals must quickly increase their capacity for admission.

Unfortunately, there are serious concerns about the triage knowledge of nurses. In different studies, nurses and nursing students' knowledge and practice of triage at the time of disasters have been assessed and reported poor or less than average level. Stiell et al. reported average triage practice of Canadian emergency department nurses [12]. In the study of Meyer et al. , nurses in emergency centers of a hospital in South Africa had moderate triage practice [13]. Rabeian et al. reported average triage practice level for nurses of teaching hospitals affiliated to Tehran University of Medical Sciences during disasters [14].

At the time of disasters, the speed of delivering emergency services in health centers is of particular importance in reducing mortality and morbidity. On the other hand, assessing the knowledge and practice of nurses in different educational centers can reveal the necessity of initial education and holding training workshops in the covered centers. Moreover, there is no study on evaluating the preparedness of nurses for performing disaster triage. In this regard, this study attempts to investigate nurses' knowledge and practice of disaster triage in hospitals affiliated to Ilam University of Medical Sciences (IUMS). 


\section{Materials and Methods}

The present study is a descriptive and analytic study conducted in 2017. Statistical population consists of all nurses working in hospitals affiliated to IUMS, including Imam Khomeini, Shahid Mostafa Khomeini, Ayatollah Taleghani, Imam Ali, Imam Reza, Imam Hossein, Shohada, Valiasr, and Rasul-e Akram hospitals ( $n=319)$. Using the Cochran formula and random sampling technique, the sample size was obtained as 174, of which 160 received a questionnaire and returned them after one day. Inclusion criteria were having at least 6 months of experience in the emergency department and willingness to participate in the study. The study samples were assured that their information would be kept confidential.

The data collection tool was a researcher-made questionnaire based on the Canadian Triage and Acuity Scale (CTAS). The CTAS has been used in many studies with acceptable reliability and validity [15-17]. The questionnaire has three sections; first section surveys demographic characteristics of the participants (age, gender, marital status, educational level, and work experience in emergency). The second section assesses the triage knowledge of nurses with 15 questions, one point for each correct answer and 0 for the wrong ones. The total score ranges from 0 to 15 . The third section evaluates the triage practice of subjects. It has 15 case questions, according to each case, the participants' decision making and actions are assessed at each level of triage, one point for each correct answer and 0 for the wrong ones. The total score of questionnaire was 30 . The score less than $50 \%$ of the total score indicates poor level; the score between $50 \%$ and $75 \%$ shows moderate level; and the score higher than $75 \%$ of total score indicates high level of knowledge and practice.

Validity of the questionnaire was assessed and confirmed by ten faculty members of the IUMS, and the reliability of the questionnaire for the triage knowledge and practice sections were reported 0.83 and 0.79 , respectively using the Cronbach $\alpha$ coefficient. The collected data were analyzed in SPSS v.19 by performing descriptive and inferential statistics.

\section{Results}

Of nurses participated in this study, 92 (57.5\%) were female with a Mean \pm SD age of $30 \pm 4.11$ years, and 68 $(45.5 \%)$ were men with a Mean \pm SD age of $31 \pm 5.12$ years. Moreover, $62.5 \%$ of participants were married and $37.5 \%$ were single. Their mean work experience was $5.2 \pm 3.04$ years where $46.2 \%$ had triage experience (Table 1 ).

Table 1. Demographic characteristics of the participants

\begin{tabular}{|c|c|c|c|}
\hline \multicolumn{2}{|c|}{ Group } & \multirow{2}{*}{$\begin{array}{c}\text { No. } \\
68\end{array}$} & \multirow{2}{*}{$\begin{array}{c}\% \\
42.5\end{array}$} \\
\hline & Male & & \\
\hline Gender & & & \\
\hline & Female & 92 & 87.5 \\
\hline \multirow{5}{*}{ Age groups, y } & $20-25$ & 48 & 30 \\
\hline & $26-30$ & 52 & 32.5 \\
\hline & & & \\
\hline & $31-35$ & 37 & 23.2 \\
\hline & $>35$ & 23 & 14.3 \\
\hline \multirow{3}{*}{ Educational level } & High school diploma or lower & 32 & 20 \\
\hline & Bachelor degree & 86 & 53.7 \\
\hline & Master degree or higher & 42 & 26.3 \\
\hline \multirow{4}{*}{ Work experience, $y$} & $1-5$ & 32 & 20 \\
\hline & $6-10$ & 37 & 23.2 \\
\hline & $11-15$ & 39 & 24.3 \\
\hline & $>16$ & 52 & 32.5 \\
\hline
\end{tabular}


Table 2. Correlation test results between triage knowledge and practice of nurses in terms of demographic characteristics

\begin{tabular}{|c|c|c|}
\hline \multirow{2}{*}{$\begin{array}{l}\text { Demographic } \\
\text { Characteristics }\end{array}$} & \multicolumn{2}{|c|}{ Sig. (r) } \\
\hline & Triage Knowledge & Triage Practice \\
\hline Age & $0.3(0.9)$ & $0.8(0.11)$ \\
\hline Work experience & $0.4(0.10)$ & $0.2(0.7)$ \\
\hline Gender & $0.16(0.67)$ & $0.7(0.22)$ \\
\hline Educational level & $0.009(6.1)$ & $0.006(5.09)$ \\
\hline
\end{tabular}

The Mean \pm SD triage knowledge score of nurses was $10.44 \pm 2.11$ out of 15 and their Mean \pm SD triage practice was $9.72 \pm 2.14$. This shows that their triage knowledge was higher than their triage practice, while both was at moderate level. Statistical test results indicated no significant relationship between triage knowledge and practice of nurses with age, gender, and work experience; however, a significant relationship was found between them and educational level (Table 2).

\section{Discussion}

One of the important indicators of disaster preparedness is to examine the level of triage knowledge and practice of emergency personnel. This study aimed to determine the knowledge and practice of nurses working in IUMS hospitals regarding triage. The results indicate that nurses' triage knowledge and practice were at moderate level. Aghababaeian et al. in their study also reported pre-hospital average knowledge and practice triage for emergency medical services staff in Khuzestan Province, Iran [18]. However, in Javadi et al. study, emergency department nurses in teaching hospitals affiliated to Shahid Sadoughi University of Medical Sciences and Health Services in Yazd Province had poor triage knowledge and practice level [19]. Rahmani et al. in evaluating the knowledge and skill of disaster management team in Shahid Rajaei Hospital, Gachsaran, Iran regarding disaster triage, reported that their disaster triage knowledge and skill was poor [20]. Similar to this study, Haghigh et al. reported that the triage knowledge of nurses in teaching hospitals affiliated to Ahwaz University of Medical Sciences was undesirable [21].

A review of the studies conducted in Iran indicates that the level of triage knowledge and practice of nurses in both normal and critical conditions (disasters) is moderate or poor. This shortcoming calls for providing educational trainings courses in the field of triage at the time of disasters for different hospital staff in Iran, especially those working in the emergency departments. In Reay et al. study [22], emergency department nurses in Canada had high triage decision making, while in Tzeng et al. study [23], majority of hospital nurses in Taiwan demonstrated poor readiness for disaster responses.

In the current study, nurses' disaster triage knowledge was higher than their practice, which shows that their education and theoretical knowledge is higher than practical knowledge. This is consistent with the findings of Javadi et al. and Rahmani et al. [19-20], but disagrees with Aghababaeian et al. [18]. In examining the effect of demographic characteristics on triage knowledge and practice of nurses, results of our study showed that age, gender, and work experience of nurses had no association with triage knowledge and practice, but their educational level has significant relationship with their triage knowledge and practice. In Haghigh et al. study, gender and work experience had association with nurses' triage knowledge [21], while in Aghababaeian et al. study, emergency medical services staffs' education had correlation with their knowledge and performance regarding prehospital triage which is consistent with our results [18].

\section{Conclusion}

The results indicate that nurses' triage knowledge and practice were at moderate level. In addition, their triage knowledge was higher than their practice, which shows that their education and theoretical knowledge is higher than practical knowledge. It is recommended that emergency departments of hospitals in Iran use sustainable scales for nurses' better judgment and agreement over patients' condition (triage) along with equipping them with trained human resources and triage tools. Development of a national triage scale and granting of a professional emergency nursing license can provide a good basis for knowledge-based practice for nurses. 
Nursing triage with an emphasis at the time of disasters as a situation where nurses play an important role in treating injuries, can be a proper ground for the richness of emergency nursing. Moreover, during disasters, if the patients are not well prioritized at the very first moments of hospitalization, they may not be helped during the next few hours. In other words, triage is as an information-related profession. Nurses with correct knowledge of triage provide appropriate treatment for the patient. Therefore, the nurses' weakness in triage can negatively affect the quality of treatment.

\section{Ethical Considerations}

\section{Compliance with ethical guidelines}

All participants were allowed to withdraw from the study at any time. This study was conducted according to the ethical guidelines No. 7, 8, 17 provided by the Ethics Committee of Medical Sciences University.

\section{Funding}

This research did not receive any specific grant from funding agencies in the public, commercial, or not-forprofit sectors.

\section{Authors contributions}

The authors contributions is as follows: Heshmatolah Asgari: Data collection and analysis; Mohammad Reza Omidi: Writing text and doing calculations; and Nabi Omidi: Interviewing and distributing questionnaires.

\section{Conflict of interest}

The authors declare no conflict of interest.

\section{Acknowledgements}

The authors would like to thank all nurses who kindly participated in this study.

\section{Refrence}

[1] Johnson KD, Alhaj Ali A. Using simulation to assess the impact of triage interruptions. Journal of Emergency Nursing. 2017; 43(5):435-43. [DOI:10.1016/j.jen.2017.04.008] [PMID]

[2] Firouzkouhi M, Zargham-Boroujeni A, Kako M, Abdollahimohammad A. Experiences of civilian nurses in triage during the Iran-Iraq war: An oral history. Chinese Journal of Trauma- tology. 2017; 20(5):288-92. [DOI:10.1016/j.cjtee.2017.07.002] [PMID] [PMCID]

[3] Falzone E, Pasquier P, Hoffmann C, Barbier O, Boutonnet M, Salvadori A, et al. Triage in military settings. Anaesthesia Critical Care \& Pain Medicine. 2017; 36(1):43-51. [DOI:10.1016/j. accpm.2016.05.004] [PMID]

[4] Vassallo J, Beavis J, Smith JE, Wallis LA. Major incident triage: Derivation and comparative analysis of the Modified Physiological Triage Tool (MPTT). Injury. 2017; 48(5):992-9. [DOI:10.1016/j.injury.2017.01.038] [PMID]

[5] Abdolahzadeh F, Lotfi M, HassanKhani H, Dadashzadeh A. [The study of triage in the hospital emergency departments of Tabriz in view of doctors and nurses in 2003 (Persian)]. Journal of Rescue and Relief. 2014; 5(4):34-46.

[6] Rouhani SA, Aaronson E, Jacques A, Brice S, Marsh RH. Evaluation of the implementation of the South African triage system at an academic hospital in central Haiti. International Emergency Nursing. 2017; 33:26-31. [DOI:10.1016/j. ienj.2016.12.004] [PMID]

[7] Thomas D, Kircher J, Plint AC, Fitzpatrick E, Newton AS, Rosychuk RJ, et al. Pediatric pain management in the emergency department: The triage nurses' perspective. Journal of Emergency Nursing. 2015; 41(5):407-13. [DOI:10.1016/j. jen.2015.02.012] [PMID]

[8] Matz K, Britt T, LaBond V. CT ordering patterns for abdominal pain by physician in triage. The American Journal of Emergency Medicine. 2017; 35(7):974-7. [DOI:10.1016/j. ajem.2017.02.003] [PMID]

[9] Hossein Mardi A, Khaghani A, MacDonald AB, Nguyen P, Karimi N, Heidary P, et al. The lake Urmia environmental disaster in Iran: A look at aerosol pollution. Science of The Total Environment. 2018; 633(15):42-9. [DOI:10.1016/j.scitoe tenv.2018.03.148] [PMID] [PMCID]

[10] Alizadeh M, Iremlow A, Alizadeh B, Shakibi A, Aliloo L. [A Survey to examin the emergency nurses operation \& comparing it with international standards in the hospital of Urmia Medical Sciences University (Persian)]. Journal of Urmia Nursing And Midwifery Faculty. 2010; 8(3):156-61.

[11] Hinds N, Borah A, Yoo EJ. Outcomes of nighttime refusal of admission to the intensive care unit: The role of the intensivist in triage. Journal of Critical Care. 2017; 39:214-9. [DOI:10.1016/j.jcrc.2016.12.024] [PMID]

[12] Stiell IG, Clement CM, Lowe M, Sheehan C, Miller J, Armstrong S, et al. A multicenter program to implement the Canadian C-Spine rule by emergency department triage nurses. Annals of Emergency Medicine. 2018; 72(4):333-41. [DOI:10.1016/j.annemergmed.2018.03.033] [PMID]

[13] Meyer GD, Meyer TN, Gaunt CB. Validity of the South African Triage Scale in a rural district hospital. African Journal of Emergency Medicine. 2018; 8(4):145.-9. [DOI:10.1016/j. afjem.2018.07.004]

[14] Rabeian M, Hosseini SH, Radabadi M, Taheri Mirghaed M, Bakhtiari M. [Evaluation of effective factors on the rate of preparedness of Tehran University of Medical Sciences' selected hospitals in dealing with earthquake (Persian)]. Journal of Payavard Salamat. 2013; 7(3):251-61.

[15] Downey LVA, Zun LS, Burke T. Comparison of Canadian triage acuity scale to Australian emergency mental health 
Scale triage system for psychiatric patients. International Emergency Nursing. 2015; 23(2):138-43. [DOI:10.1016/j. ienj.2014.06.006] [PMID]

[16] Ng CJ, Hsu KH, Kuan JT, Chiu TF, Chen WK, Lin HJ, et al. Comparison between Canadian triage and acuity scale and Taiwan triage system in emergency departments. Journal of the Formosan Medical Association. 2010; 109(11):828-37. [DOI:10.1016/S0929-6646(10)60128-3]

[17] Smith DT, Snyder A, Hollen PJ, Anderson JG, Caterino JM. Analyzing the usability of the 5-level Canadian triage and acuity scale by paramedics in the prehospital environment. Journal of Emergency Nursing. 2015; 41(6):489-95. [DOI:10.1016/j.jen.2015.03.006] [PMID]

[18] Aghababaeian H, Sedaghat S, Taheri N, Mousavi SA, Habibi-Moghadam M, Pourmotahari F. [Evaluating knowledge and performance of emergency medical services staff regarding pre-hospital triage (Persian)]. 2017; 4(2):63-7.

[19] Javadi S, Salimi T, Sareban MT, Dehghani MA. [Knowledge and practice of nurses regarding patients' triage in emergency department (Persian)]. Iranian Journal of Emergency Medicine. 2016; 3(1):15-22.

[20] Rahmani E, Khani Jeihooni A, Hosseini Fahraji H. [Knowledge and skill of hospital's disaster committee regarding Triage at times of crisis; A cross-sectional study (Persian)]. Iranian Journal of Emergency Medicine. 2016; 3(4):143-8.

[21] Haghigh S, Ashrafizadeh H, Mojaddami F, kord B. [A survey on knowledge level of the nurses about hospital triage (Persian)]. Journal of Nursing Education. 2017; 5(6):46-52. [DOI:10.21859/jne-05067]

[22] Reay G, Rankin JA, Then KL. Momentary fitting in a fluid environment: A grounded theory of triage nurse decision making. International Emergency Nursing. 2016; 26:8-13. [DOI:10.1016/j.ienj.2015.09.006] [PMID]

[23] Tzeng WC, Feng HP, Cheng WT, Lin CH, Chiang LC, Pai $\mathrm{L}$, et al. Readiness of hospital nurses for disaster responses in Taiwan: A cross-sectional study. Nurse Education Today. 2016; 47:37-42. [DOI:10.1016/j.nedt.2016.02.025] [PMID] 